Pembuatan Velva Kominasi Jambu Biji dan Belimbing Manis - Arrasyid, dkk Jurnal Pangan dan Agroindustri Vol.7 No.2: 24-36, April 2019

\title{
PEMBUATAN VELVA KOMBINASI JAMBU BIJI DAN BELIMBING MANIS (KAJIAN PROPORSI BUAH DAN KONSENTRASI GUM ARAB)
}

\section{Making Velva Combining Guava and Starfruit (Focus on Proportion fruit and Concentration of Gom Arab)}

\author{
Hamzah Halim Arrasyid*, Siti Narsito Wulan \\ Jurusan Teknologi Hasil Pertanian, FTP Universitas Brawijaya Malang \\ JI. Veteran, Malang 65145 \\ *Penulis Korespondensi, Email: hamzah.arrasyid2@gmail.com
}

\section{RINGKASAN}

Penelitian ini bertujuan untuk mengetahui rasio perbandingan antara buah jambu biji dan belimbing manis serta konsentrasi gum arab terhadap sifat kimia, fisik, dan organoleptik. Penelitian menggunakan racangan acak kelompok (RAK) dengan 2 faktor dan 3 kali ulangan. Faktor pertama yaitu proporsi perbandingan antara buah jambu biji dan belimbing manis (2:1, $1: 1$, dan $1: 2)$ dan faktor kedua yaitu konsentrasi gum arab $(0.5 \%, 1 \%)$. Hasil penelitian menunjukkan perlakuan terbaik didapatkan pada perlakuan proporsi buah jambu biji : belimbing manis $1: 1$ dengan konsentrasi gum arab $0.5 \%$ dengan karakteristik $\mathrm{pH} 3.64$; kadar serat kasar $0.86 \%$; aktivitas antioksidan $10.19 \%$; TPT $14.46^{\circ}$ Brix; overrun $13.01 \%$; kecepatan meleleh 20.84 menit/10 gram; kecerahan $L^{*}$ 45.26; kemerahan $a^{*} 11.03$; dan kekuningan $b^{*}$ 16.16, nilai hedonik dengan skala 1-6 (sangat tidak suka sampai sangat suka) pada warna 3.60 (agak tidak suka - agak suka); aroma 4.04 (agak suka); rasa 4.12 (agak suka); dan tekstur 3.64 (agak tidak suka - agak suka).

Kata kunci: Belimbing, Gum Arab, Jambu Biji, Velva

\section{ABSTRACT}

This study aimed to determine the optimum ratio between guava and starfruit and the concentration of arabic gum on chemical, physical, and sensory properties of velva. The two factorial Randomized Block Design (RBD) was applied. The first factor was the ratio of guava and starfruit (2:1, 1:1 and 1:2) and the second factor was the concentration of arabic gum $(0.5 \%$ and $1 \%)$. The results showed the best treatment was obtained from a combination of the ratio of guava : starfruit $(1: 1)$ and $0.5 \%$ concentration of arabic gum. The velva characteristics were as follows: $\mathrm{pH} 3.69 ; 1.92 \%$ crude fiber content; antioxidant activity of $10.19 \%$; TSS of $14.46^{\circ}$ Brix; overrun of $13.01 \%$; melting rate of 20.84 minutes /10 grams; Lightness of 45.26; redness of 11.03; and yellowness of 16.16. Sensory evaluation on hedonic scale of 1-6 (very dislike to very like) showed that color, aroma, taste and texture liking were 3.60 (rather like); 4.04 (rather like); 4.12 (rather like); and 3.64 (rather like) respectively.

Keywords: Starfruit, Guava, Arabic Gom, Velva

\section{PENDAHULUAN}

Penggunaan jambu biji sebagai bahan dasar pembuatan produk pangan semakin meningkat pada beberapa tahun terakhir. Hal ini didasarkan pada keunggulan-keunggukan yang dimiliki oleh jambu biji. Sebutir jambu biji dengan berat $275 \mathrm{~g}$ per buah dapat mencukupi kebutuhan harian akan vitamin $\mathrm{C}$ pada tiga orang dewasa atau dua anak-anak. Belimbing merupakan buah yang banyak mengandung air dan tinggi vitaminn $\mathrm{C}$ dan serat kasar. Buah 
belimbing memiliki manfaat sebagai antioksidan dan anti bakteri (Sukadana, 2009). Akan tetapi pada buah jambu biji dan belimbing manis memiliki kelemahan yaitu masa simpan yang singkat sehingga buah jambu biji dan buah belimbing yang disimpan akan mudah rusak, oleh karena kelemahan itu maka peneliti melakukan penelitian membuat produk olahan dari kombinasi buah belimbing dan buah jambu biji, sehingga masa simpan buah jambu biji dan buah belimbing menjadi lebih panjang daripada sebelum di olah.

Salah satu bentuk olahan yang dapat dikembangkan adalah velva fruit. Velva fruit adalah produk frozen dessert yang berasal dari campuran bubur buah, gula, dan bahan penstabil. Keunggulan velva adalah kandungan vitamin dan serat pangan yang tinggi serta kandungan lemak yang cukup rendah. Velva fruit juga tidak menggunakan susu ataupun telur sehingga dapat dikonsumsi oleh banyak orang, terutama vegetarian dan penderita lactose intolerance (Musaddad, 2000).

Pada penelitian ini bertujuan menemukan rasio perbandingan buah jambu biji dan buah belimbing yang dipergunakan untuk menemukan perbandingan rasio terbaik dan penerimaan terbaik pada produk velva kombinasi buah jambu biji dan buah belimbing.

\section{BAHAN DAN METODE}

\section{Alat}

Timbangan analitik merek $\mathrm{CHQ}$, sendok, pisau, blender merek Miyako, baskom, toples plastik, kompor, panci, thermometer, ice cream maker merek Gaggie Gelatira, freezer, dan refrigerator. Alat yang dipergunakan untuk analisis produk velva adalah tensil strength, $\mathrm{pH}$ Meter, stopwatch, colour reader, bulb, cawan petri, erlenmayer $250 \mathrm{ml}$ merek Pyrex, gelas ukur $100 \mathrm{ml}$ merek Pyrex, pipet volume $1 \mathrm{ml}$ dan $10 \mathrm{ml}$ merek Pyrex, labu ukur $100 \mathrm{ml}$ dan $250 \mathrm{ml}$ merek Pyrex, pipet tetes, spektofotometer merek Labomeld, shaker merek Heidorph dan spatula kaca.

\section{Bahan}

Buah jambu biji merah dan buah belimbing manis varietas Dewi yang dipanen di kota Batu. Bahan untuk pembuatan velva yaitu sukrosa merek Gulaku, air mineral, agar-agar merek Swallow, dan gum arab merek Al-Manna Arabic Gum Powder. Bahan yang dipergunakan untuk analisis adalah aquadest, $\mathrm{DPPH}$, etanol, $\mathrm{K}_{2} \mathrm{SO}_{4}, \mathrm{NaOH} 0.1 \mathrm{~N}$, asam oksalat, Indikator PP, lodium $0.01 \mathrm{~N}$, dan asam askorbat murni.

\section{Tahapan Penelitian}

Perbandingan rasio bubur buah jambu biji : buah belimbing manis 2:1, 1:1, $1: 2(\mathrm{v} / \mathrm{v})$ ditakar sejumlah bahan-bahan yang digunakan, gum arab $1 \%$ dan $2 \%$ (v/v) dicampurkan sesuai perlakuan, sukrosa $10 \%$, agar (0.2\%), dan air mineral (50\%), dilakuakan pencampuran dengan blender kecepatan 2 selama 2 menit, dipasteurisasi pada suhu $85^{\circ} \mathrm{C}$ selama 15 detik, Dilakukan pendinginan di suhu ruang selama 30 detik, Dilakukan aging dalam refrigerator pada suhu $4^{\circ} \mathrm{C}$ selama 24 jam, dilakukan pembekuan di dalam ice cream maker pada suhu $5^{\circ} \mathrm{C}$ selama 30 menit, dilakukan pengerasan dalam freezer dengan suhu $-20^{\circ} \mathrm{C}$ selama 24 jam.

\section{Pengujian dan Analisis}

Analisis pada velva meliputi analisis kimia meliputi $\mathrm{pH}$ dengan $\mathrm{pH}$ meter, analisis aktivitas antioksidan, analisi serat kasar, analisis fisik antara lain total padatan terlarut (TPT), overrun, kecepatan leleh, dan warna dengan colour reader, analisis organoleptik meliputi analisis kesukaan terhadap aroma, rasa, tekstur, dan warna velva.

\section{Metode}

Penelitian menggunakan racangan acak kelompok (RAK) dengan menggunakan dengan menggunakan dua faktor, dimana faktor I terdiri dari 3 level dan faktor II terdiri 2 level. Masing-masing level diulang sebanyak 3 kali sehinmgga diperoleh 18 satuan percobaan.. Faktor 1 yaitu rasio perbandingan antara buah jambu biji dan belimbing manis, A1 rasio buah 
2:1 (v/v), A2 rasio buah 1:1 (v/v), dan A3 rasio buah 1:2 (v/v) dan faktor 2 yaitu persentase penambahan konsentrasi gum arab G1 $0.5 \%$ dan G2 konsentrasi 1\% dari total slury.

\section{HASIL DAN PEMBAHASAN}

\section{Karakteristik Kimia Bahan Baku}

Bahan baku yang dianalisis adalah buah jambu biji dan buah belimbing, sedangkan Analisis yang dilakukan pada bahan baku meliputi analisis kadar serat kasar, $\mathrm{pH}$, total padatan terlarut (TPT), kadar air, dan aktivitas antioksidan. Analisis bahan baku dilakukan pada kondisi buah jambu biji merah dan buah belimbing telah dihancurkan atau telah menjadi bubur buah. Analisis bahan baku dapat dilihat pada Tabel 1.

Tabel 1. Rerata Karakteristik Kimia Bahan Baku

\begin{tabular}{ccc}
\hline \multirow{2}{*}{ Komponen } & \multicolumn{2}{c}{ Hasil Analisis } \\
\cline { 2 - 3 } & Jambu Biji Merah & Belimbing \\
\hline Kadar serat kasar (\%) & $2.12 \pm 0.35$ & $2.67 \pm 0.29$ \\
pH & $4.75 \pm 0.17$ & $4.29 \pm 0.09$ \\
TPT ('Brix) & 8.67 & 7.73 \\
Kadar Air (\%) & 83.30 & 89.96 \\
Aktivitas Antioksidan (\%) $^{*}$ & $46.82 \pm 0.65$ & $33.37 \pm 0.89$ \\
\hline
\end{tabular}

Keterangan : Setiap data hasil analisis merupakan rerata dari 3 ulangan

\section{2. $\mathrm{pH}$}

Pada Prinsipnya analisis pengukuran $\mathrm{pH}$ diperoleh dari pengukuran konsentrasi ion hidrogen dalam medium akibat asam-asam yang terdisosiasi. Semakin tinggi ion $\mathrm{H}^{+}$dalam medium maka semakin rendah $\mathrm{pH}$.. Hasil analisis ragam menunjukkan bahwa perbandingan konsentrasi buah jambu biji dan belimbing memberikan pengaruh nyata $(\alpha=0.05)$ terhadap $\mathrm{pH}$ velva, sedangkan penambahan konsentrasi gum arab memberikan pengaruh tidak nyata $(\alpha=$ 0.05) terhadap $\mathrm{pH}$ velva. Kemudian interaksi antar kedua faktor memberikan pengaruh tidak nyata, Rerata $\mathrm{pH}$ velva yang dipengaruhi oleh rasio jambu biji dan belimbing dapat dilihat pada Tabel 2.

Tabel 2. Rerata pH Akibat Rasio Buah Jambu Biji dan Buah Belimbing

\begin{tabular}{cc}
\hline Rasio Jambu Biji : Belimbing & Rerata $\mathrm{pH}$ \\
\hline $2: 1$ & $3.86 \pm 0.18 \mathrm{~b}$ \\
$1: 1$ & $3.70 \pm 0.10 \mathrm{a}$ \\
$1: 2$ & $3.64 \pm 0.10 \mathrm{a}$ \\
\hline BNT 5\% & 0.10 \\
\hline
\end{tabular}

Keterangan: 1) Setiap data merupakan rerata dari 3 kali ulangan

2) Angka yang didampingi notasi berbeda menunjukkan perbedaan nyata $(\alpha=0.05)$

Tabel 2. menunjukkan nilai $\mathrm{pH}$ cenderung terendah diperoleh pada perlakuan rasio jambu biji : belimbing $2: 1$ sebesar 3.86 Perbedaan nilai $\mathrm{pH}$ tersebut terjadi dikarenakan pada perlakuan rasio jambu biji : belimbing, buah belimbing lebih asam dibandingkan buah jambu biji sehingga pada perlakuan rasio jambu biji : belimbing $1: 2$ akan memiliki tingkat $\mathrm{pH}$ cenderung lebih tinggi.

$\mathrm{pH}$ pada Velva Kombinasi Buah Jambu Biji dan Buah Belimbing dipengaruhi oleh tingkat keasaman kombinasi pada buah jambu biji dan buah belimbing yang akan menurunkan $\mathrm{pH}$ dari produk velva tersebut. Pada produk velva tingkat keasaman $(\mathrm{pH})$ merupakan faktor penting pada produk frozzen desert. Semakin besar jumlah total padatan di dalam es krim maka keasaman es krim akan semakin tinggi sehingga berpotensi menurunkan $\mathrm{pH}$. Keasaman yang terlalu tinggi pada produk velva tidak diinginkan karena akan meningkatkan 
kekentalan dan mengurangi pengembangan pada velva kombinasi buah jambu biji dan buah belimbing (Maria, 2014).

\section{Serat Kasar}

Serat kasar adalah bagian dari pangan yang tidak dapat dihidrolisis oleh asam atau basa kuat, dan tidak larut dalam air. Hasil analisis ragam menunjukkan bahwa perbandingan konsentrasi buah jambu biji dan belimbing memberikan pengaruh nyata $(\alpha=0.05)$ terhadap serat kasar velva, sedangkan penambahan konsentrasi gum arab memberikan pengaruh tidak nyata $(\alpha=0.05)$ terhadap serat kasar velva. Interaksi antar kedua faktor tidak memberikan pengaruh nyata. Rerata serat kasar velva yang dipengaruhi rasio jambu biji dan belimbing dapat dilihat pada Tabel 3.

Tabel 3. Rerata Serat Kasar Akibat Rasio Buah Jambu Biji dan Buah Belimbing

\begin{tabular}{cc}
\hline Rasio Jambu Biji : Belimbing & Rerata Serat Kasar (\%) \\
\hline $2: 1$ & $0.82 \pm 0.26 \mathrm{a}$ \\
$1: 1$ & $0.90 \pm 0.22 \mathrm{a}$ \\
$1: 2$ & $1.41 \pm 0.33 \mathrm{~b}$ \\
\hline BNT 5\% & 0.14
\end{tabular}

Keterangan: 1) Setiap data merupakan rerata dari 3 kali ulangan

2) Angka yang didampingi notasi berbeda menunjukkan perbedaan nyata $(\alpha=0.05)$

Tabel 3. menunjukkan nilai serat kasar cenderung tertinggi diperoleh pada perlakuan rasio jambu biji : belimbing $1: 2$ sebesar $1.41 \%$. Berdasarkan tabel diatas dapat disimpulkan bahwa semakin banyak rasio buah belimbing yang ditambahkan pada proses pembuatan velva maka nilai serat kasar velva akan semakin tinggi. Perbedaan nilai serat kasar tersebut terjadi dikarenakan buah belimbing lebih banyak mengadung serat kasar dibandingkan buah jambu biji (tabel 4.1) sehingga pada perlakuan rasio jambu biji : belimbing $1: 2$ akan memiliki tingkat serat kasar paling tinggi.

\section{Aktivitas Antioksidan}

Hasil analisis persentase aktivitas antioksidan velva kombinasi buah jambu biji dan buah belimbing manis berkisar $8.55 \%-12.94 \%$. Hasil analisis ragam menunjukkan bahwa perbandingan konsentrasi buah jambu biji dan belimbing memberikan pengaruh nyata $(\alpha=0.05)$ terhadap persentase aktivitas antioksidan velva, sedangkan penambahan konsentrasi gum arab memberikan pengaruh tidak nyata $(\alpha=0.05)$ terhadap persentase aktivitas antioksidan velva. Sedangkan interaksi antar kedua faktor memberikan pengaruh tidak nyata, sehingga dilakukan uji lanjut BNT. Rerata aktivitas antioksidan velva yang dipengaruhi rasio jambu biji dan buah belimbing dapat dilihat pada Tabel 4.

Tabel 4. Rerata persentase Aktivitas Antioksidan Akibat Rasio Buah Jambu Biji Dan Buah Belimbing

\begin{tabular}{cc}
\hline Rasio Jambu Biji : Belimbing & Rerata Aktivitas Antioksidan (\%) \\
\hline $2: 1$ & $12.64 \pm 0.90 \mathrm{c}$ \\
$1: 1$ & $10.36 \pm 0.48 \mathrm{~b}$ \\
$1: 2$ & $8.72 \pm 0.83 \mathrm{a}$ \\
\hline BNT 5\% & 0.56 \\
\hline
\end{tabular}

Keterangan: 1) Setiap data merupakan rerata dari 3 kali ulangan

2) Angka yang didampingi notasi berbeda menunjukkan perbedaan nyata $(\alpha=0.05)$

Tabel 4. menunjukkan nilai persentase aktivitas antioksidan tertinggi diperoleh pada perlakuan rasio jambu biji : belimbing 2 : 1 sebesar 12.64\% Peningkatan nilai persentase aktivitas antioksidan tersebut terjadi dikarenakan pada perlakuan rasio jambu biji : belimbing, 
buah jambu biji yang lebih banyak rasionya maka kandungan vitamin $\mathrm{C}$ pada produk velva akan lebih tinggi dan persentase aktivitas antioksidannya akan lebih tinggi. Kandungan asam askorbat (vitamin C) pada buah jambu biji sebanyak 200-400 mg per 100 gram berat buahnya. Sedangkan pada buah belimbing hanya memeliki vitamin c sebanyak $35 \mathrm{mg}$ per 100 gramnya (Soedarya, 2009).

Kandungan asam askorbat (vitamin C) yang merupakan antioksidan tertinggi pada produk velva dapat tetap terjaga dengan baik dan relatif stabil dikarenakan pada buah yang memeiliki pH yang rendah dengan kandungan serat yang tinggi (Andarwulan, 1992). Hal ini menyebabkan terciptanya korelasi antara persentase aktivitas antioksidan dan $\mathrm{pH}$ pada produk velva yang ditunjukan pada Gambar 1.

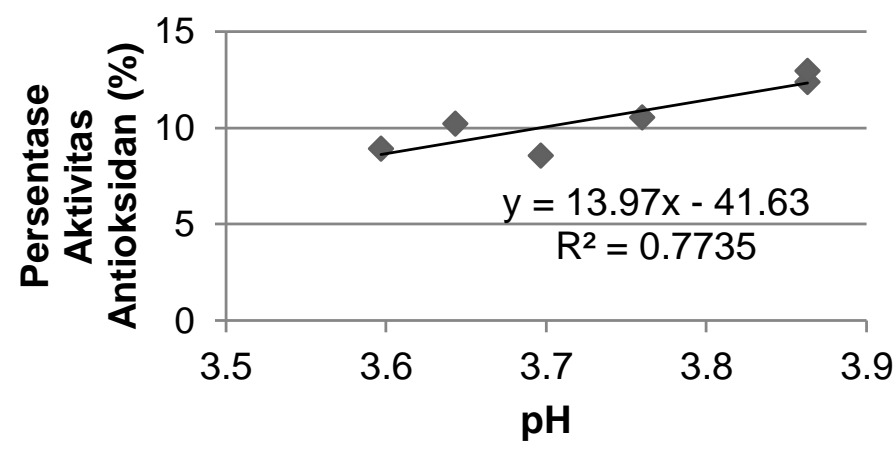

Gambar 1. Grafik hubungan antara nilai ph dengan persentase aktifitas antioksidan velva kombinasi buah jambu biji dan buah belimbing dan konsentrasi gum arab

Gambar 1. memperlihatkan grafik hubungan antara nilai $\mathrm{pH}$ dengan persentase aktivitas antioksidan. Berdasarkan analisis regresi linear antara nilai $\mathrm{pH}$ dengan persentase aktivitas antioksidan pada konsentrasi $500 \mathrm{ppm}$ diperoleh persamaan $\mathrm{y}=0.055 \mathrm{x}+3.151$ dengan koefisien determasi $R^{2}=0.773$, dari persamaan tersebut dapat diartikan bahwa persentase aktivitas antioksidan dipengaruhi oleh nilai $\mathrm{pH}$ dan menunjukan korelasi positif, dimana semakin tinggi nilai $\mathrm{pH}$ maka persentase aktivitas antioksidan semakin naik. Kontribusi $\mathrm{pH}$ pada persentase aktivitas antioksidan sebesar $77.3 \%$.

\section{Total Padatan Terlarut (TPT)}

Hasil analisis total padatan terlarut velva kombinasi buah jambu biji dan buah belimbing manis berkisar $14.40^{\circ}$ Brix $-15.46^{\circ}$ Brix. Hasil analisis ragam menunjukkan bahwa perbandingan konsentrasi buah jambu biji dan belimbing memberikan pengaruh nyata $(\alpha=0.05)$ terhadap total padatan terlarut velva, sedangkan penambahan konsentrasi gum arab memberikan pengaruh tidak nyata $(\alpha=0.05)$ terhadap total padatan terlarut velva. Kemudian interaksi antar kedua faktor memberikan pengaruh tidak nyata, sehingga dilakukan uji lanjut BNT. Rerata total padatan terlarut velva yang dipengaruhi rasio jambu biji dan belimbing dapat dilihat pada Tabel 5.

Tabel 5. Rerata Total Padatan Terlarut Akibat Rasio Buah Jambu Biji dan Buah Belimbing

\begin{tabular}{cc}
\hline Rasio Jambu Biji : Belimbing & Rerata Total Padatan Terlarut ('Brix) \\
\hline $2: 1$ & $15.06 \pm 2.80 \mathrm{~b}$ \\
$1: 1$ & $14.43 \pm 2.94 \mathrm{a}$ \\
$1: 2$ & $15.43 \pm 3.10 \mathrm{~b}$ \\
\hline BNT $5 \%$ & 0.53
\end{tabular}

Keterangan: 1) Setiap data merupakan rerata dari 3 kali ulangan

2) Angka yang didampingi notasi berbeda menunjukkan perbedaan nyata $(\alpha=0.05)$ 
Tabel 4.5 menunjukkan nilai total padatan terlarut cenderung tertinggi diperoleh pada perlakuan rasio jambu biji : belimbing $1: 2$ sebesar $15.43^{\circ}$ Brix. Tabel 4.5 menunjukan velva dengan perlakuan rasio jambu biji : belimbing 1 : 1 berbeda nyata $(\alpha=0.05)$ dengan perlakuan lainnya yaitu perlakuan rasio jambu biji : belimbing $2: 1$ dan $1: 2$.

\section{Overrun}

Overrun adalah pengembangan volume yaitu kenaikan volume antara sebelum dan sesudah proses pembekuan. Hasil analisis overrun velva kombinasi buah jambu biji dan buah belimbing manis berkisar $11.97 \%-16.27 \%$. Hasil analisis ragam menunjukkan bahwa perbandingan konsentrasi buah jambu biji dan belimbing memberikan pengaruh nyata $(\alpha=0.05)$ terhadap overrun velva, sedangkan penambahan konsentrasi gum arab memberikan pengaruh nyata $(\alpha=0.05)$ terhadap overrun velva. Sedangkan interaksi antar kedua faktor memberikan pengaruh tidak nyata, sehingga dilakukan uji lanjut BNT. Kemudian rerata overrun velva kombinasi buah jambu biji dan buah belimbing manis pada Tabel 6 . dan Tabel 7.

Tabel 6. Rerata Nilai Overrun Akibat Konsentrasi Gum Arab

\begin{tabular}{cc}
\hline Konsentrasi Gum Arab (\%) & Rerata Overrun (\%) \\
\hline 0.5 & $13.28 \pm 0.51 \mathrm{a}$ \\
1 & $14.78 \pm 0.25 \mathrm{~b}$ \\
\hline BNT $5 \%$ & 0.58
\end{tabular}

Keterangan: 1) Setiap data merupakan rerata dari 3 kali ulangan

2) Angka yang didampingi notasi berbeda menunjukkan perbedaan nyata $(\alpha=0.05)$

Tabel 4.6 menunjukkan nilai overrun cenderung tertinggi ialah dengan penambahan gum arab $1 \%$ sebesar $14.78 \%$. Kemudian rerata nilai overrun velva yang dipengaruhi rasio buah jambu biji dan buah belimbing dapat dilihat pada Tabel 7 .

Tabel 7. Rerata Overrun Akibat Rasio Buah Jambu Biji dan Buah Belimbing

\begin{tabular}{cc}
\hline Rasio Jambu Biji : Belimbing & Rerata Overrun (\%) \\
\hline $2: 1$ & $12.95 \pm 0.55 \mathrm{a}$ \\
$1: 1$ & $13.57 \pm 0.32 \mathrm{~b}$ \\
$1: 2$ & $15.55 \pm 0.28 \mathrm{c}$ \\
\hline BNT 5\% & 1.50 \\
\hline
\end{tabular}

Keterangan: 1) Setiap data merupakan rerata dari 3 kali ulangan

2) Angka yang didampingi notasi berbeda menunjukkan perbedaan nyata $(\alpha=0.05)$

Tabel 7 menunjukkan nilai persentase overrun tertinggi diperoleh pada perlakuan rasio jambu biji : belimbing 1: 2 sebesar 15.55\%. Peningkatan nilai overrun tersebut terjadi dikarenakan pada buah-buah telah terdapat pati alami yang memiliki sifat dapat mengikat air, sehingga pengaruh rasio buah antara belimbing dan jambu biji dapat mempengaruhi overrun pada produk velva tersebut. Overrun pada produk es krim dan sejenisnya dipengaruhi oleh beberapa faktor, yaitu jenis votator yang digunakan, kadar protein, viskositas, dan total padatan (Maria, 2014). Dalam proses overrun adanya kandungan serat kasar pada adonan velva sangat bermanfaat sebab serat kasar dapat membuat tegangan pemukaan pada adonan menurun sehingga udara dapat menembus permukaan dan produk akan lebih mudah [9]. Hal ini menyebabkan terciptanya korelasi antara overrun dan kadar serat kasar pada produk velva yang ditunjukan pada Gambar 2. 


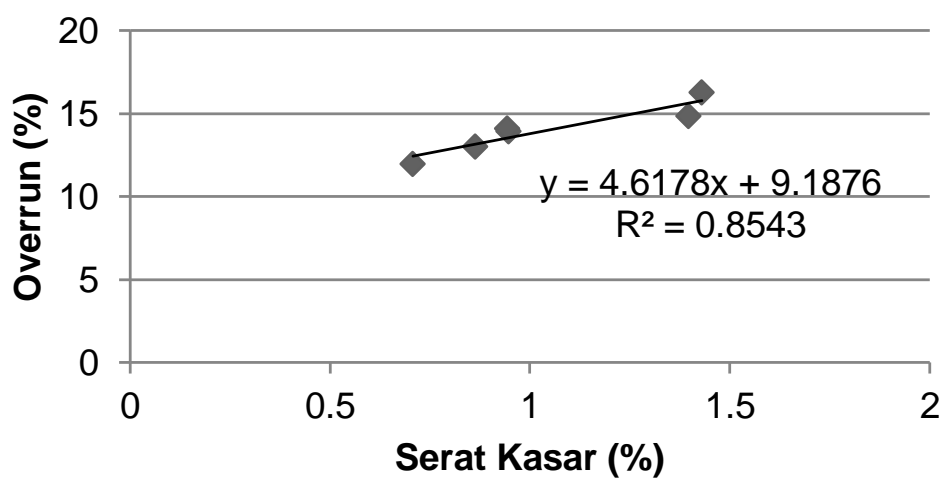

Gambar 2. Grafik hubungan antara nilai overrun dengan serat kasar velva kombinasi buah jambu biji dan buah belimbing dan konsentrasi gum arab

Gambar 2. memperlihatkan grafik hubungan antara nilai overrun dengan kadar serat kasar. Berdasarkan analisis regresi linear antara nilai overrun dengan kadar serat kasar diperoleh persamaan $y=0.185 x-1.547$ dengan koefisien determasi $R^{2}=0.854$, dari persamaan tersebut dapat diartikan bahwa overrun dipengaruhi oleh nilai serat kasar dan menunjukan korelasi positif, dimana semakin tinggi kandungan serat kasar maka overrun atau pengembangan produk velva akan semakin naik. Kontribusi serat kasar pada overrun sebesar $85.4 \%$.

\section{Kecepatan Meleleh}

Hasil analisis kecepatan meleleh velva kombinasi buah jambu biji dan buah belimbing manis berkisar 17.16 menit/10 g - 23.73 menit/ $10 \mathrm{~g}$. Hasil analisis ragam menunjukkan bahwa perbandingan konsentrasi buah jambu biji dan belimbing memberikan pengaruh nyata $(\alpha=0.05)$ terhadap kecepatan meleleh velva, sedangkan penambahan konsentrasi gum arab memberikan pengaruh tidak nyata $(\alpha=0.05)$ terhadap kecepatan meleleh velva. Kemudian interaksi antar kedua faktor memberikan pengaruh tidak nyata, Rerata kecepatan meleleh yang dipengaruhi rasio jambu biji dan belimbing dapat dilihat pada Tabel 8.

Tabel 8. Rerata Kecepatan Meleleh Akibat Rasio Buah Jambu Biji dan Buah Belimbing

\begin{tabular}{cc}
\hline Rasio Jambu Biji : Belimbing & Rerata Kecepatan Meleleh (menit/10 \\
gram) \\
\hline $2: 1$ & $18.75 \pm 1.12 \mathrm{a}$ \\
$1: 1$ & $22.30 \pm 1.90 \mathrm{~b}$ \\
$1: 2$ & $19.77 \pm 0.95 \mathrm{a}$ \\
\hline BNT 5\% & 2.94 \\
\hline
\end{tabular}

Keterangan: 1) Setiap data merupakan rerata dari 3 kali ulangan

2) Angka yang didampingi notasi berbeda menunjukkan perbedaan nyata $(\alpha=0.05)$

Tabel 8 menunjukkan nilai kecepatan meleleh tertinggi diperoleh pada perlakuan rasio jambu biji : belimbing 1 : 1 sebesar 22.30 menit/10 gram, hal ini disebabkan dimana semakinbanyak padatan dalam adonan, akan membuat adonan menjadi lebih kental sehingga pada saat pembekuan akan menurunkan titik bekunya, pada titik beku yang lebih rendah dan struktur yang lebih padat maka energi pindah panas akan terhambat sehingga waktu pelelehan akan menjadi lebih lambat (McCue, 2002).

\section{Analisis Warna}

a. Tingkat Kecerahan $\left(L^{*}\right)$

Hasil analisis ragam menunjukkan bahwa perbandingan rasio buah jambu biji dan buah belimbing memberikan pengaruh tidak nyata $(\alpha=0.05)$ terhadap warna $L^{*}$ atau tingkat 
kecerahan terhadap velva, sedangkan penambahan konsentrasi gum arab memberikan pengaruh nyata $(\alpha=0.05)$ terhadap warna velva. Sedangkan interaksi antar kedua faktor memberikan pengaruh tidak nyata terhadap tingkat kecerahan $L^{*}$. Rerata tingkat kecerahan $L^{*}$ velva ditunjukkan pada Tabel 9. .

Tabel 9. Rerata Tingkat Kecerahan Akibat konsentrasi Gum Arab

\begin{tabular}{cc}
\hline Konsentrasi Gum Arab (\%) & Tingkat kecerahan $L^{*}$ \\
\hline 0.5 & $44.17 \pm 0.85 \mathrm{a}$ \\
1 & $46.67 \pm 0.58 \mathrm{~b}$ \\
\hline BNT $5 \%$ & 2.50 \\
\hline
\end{tabular}

Keterangan: 1) Setiap data merupakan rerata dari 3 kali ulangan

2) Angka yang didampingi notasi berbeda menunjukkan perbedaan nyata $(\alpha=0.05)$

Tabel 9 menunjukkan nilai tingkat $t$ kecerahan $L^{*}$ tertinggi diperoleh dengan penambahan gum arab $1 \%$ sebesar 44.67. Tabel 4.12 menunjukan velva dengan konsentrasi gum arab $0.5 \%$ berbeda nyata $(\alpha=0.05)$ dengan perlakuan lainnya yaitu penamabahan gum $\operatorname{arab} 1 \%$.

\section{b. Tingkat Kemerahan (a*)}

Hasil analisis ragam menunjukkan bahwa perbandingan rasio buah jambu biji dan buah belimbing memberikan pengaruh nyata $(\alpha=0.05)$ terhadap warna $\mathrm{a}^{*}$ atau tingkat kemerahan velva, sedangkan penambahan konsentrasi gum arab memberikan pengaruh nyata $(\alpha=0.05)$ terhadap warna velva. Sedangkan interaksi antar kedua faktor memberikan pengaruh tidak nyata terhadap tingkat kemerahan $a^{*}$, Rerata tingkat kecerahan $a^{*}$ velva kombinasi buah jambu biji dan buah belimbing manis pada Tabel 10 dan Tabel 11.

Tabel 10. Rerata tingkat kemerahan $\mathrm{a}^{*}$ akibat konsentrasi gum arab

\begin{tabular}{cc}
\hline Konsentrasi Gum Arab $(\%)$ & Tingkat kemerahan $\mathrm{a}^{*}$ \\
\hline 0,5 & $13.93 \pm 0.67 \mathrm{a}$ \\
1 & $11.60 \pm 0.55 \mathrm{~b}$ \\
\hline BNT 5\% & 1.97 \\
\hline
\end{tabular}

Keterangan: 1) Setiap data merupakan rerata dari 3 kali ulangan

2) Angka yang didampingi notasi berbeda menunjukkan perbedaan nyata $(\alpha=0.05)$

Tabel 10 menunjukkan nilai tingkat kemerahan $\mathrm{a}^{*}$ tertinggi diperoleh dengan penambahan gum arab $0.5 \%$ sebesar 13.93. Tabel 10 menunjukan velva dengan konsentrasi gum arab berbeda nyata $(\alpha=0.05)$. Kemudian rerata tingkat kemerahan yang dipengaruhi rasio jambu biji dan belimbing dapat dilihat pada Tabel 11.

Tabel 11. Rerata Tingkat Kemerahan A* Akibat Rasio Buah Jambu Biji dan Belimbing

\begin{tabular}{cc}
\hline Rasio Jambu Biji : Belimbing & Tingkat kemerahan $\mathrm{a}^{*}$ \\
\hline $2: 1$ & $14.83 \pm 0.58 \mathrm{~b}$ \\
$1: 1$ & $11.28 \pm 0.44 \mathrm{a}$ \\
$1: 2$ & $12.18 \pm 0.81 \mathrm{a}$ \\
\hline BNT $5 \%$ & 1.61 \\
\hline
\end{tabular}

Keterangan: 1) Setiap data merupakan rerata dari 3 kali ulangan

2) Angka yang didampingi notasi berbeda menunjukkan perbedaan nyata $(\alpha=0.05)$

Tabel 11 menunjukkan nilai tingkat kemerahan $a^{*}$ tertinggi diperoleh pada perlakuan rasio jambu biji : belimbing $2: 1$ sebesar 14.83 . Tabel 11 menunjukan velva dengan perlakuan rasio jambu biji : belimbing berbeda nyata $(\alpha=0.05)$. Hal ini disebabkan rasio jambu biji merah 
lebih tinggi dari buah belimbing menyebabkan warna akan dominan menjadi merah pada produk velva kombinasi buah jambu biji dan buah belimbing.

\section{c. Tingkat Kekuningan $\left(b^{\star}\right)$}

Tingkat kekuningan $b^{*}$ menunjukkan bahwa perbandingan rasio buah jambu biji dan buah belimbing memberikan pengaruh nyata $(\alpha=0.05)$ terhadap warna $b^{*}$ atau tingkat kekuningan velva, sedangkan penambahan konsentrasi gum arab memberikan pengaruh tidak nyata $(\alpha=0.05)$ terhadap warna velva. Kemudian interaksi antar kedua faktor memberikan pengaruh tidak nyata terhadap tingkat kekuningan $b^{*}$. Rerata tingkat kekuningan $b^{*}$ yang dipengaruhi rasio jambu biji dan belimbing dapat dilihat pada Tabel 12 .

Tabel 12. Rerata Tingkat Kekuningan Akibat Rasio Buah Jambu Biji dan Belimbing

\begin{tabular}{cc}
\hline Rasio Jambu Biji : Belimbing & Tingkat kekuningan \\
\hline $2: 1$ & $13.68 \pm 0.68 \mathrm{a}$ \\
$1: 1$ & $15.95 \pm 1.04 \mathrm{~b}$ \\
$1: 2$ & $15.25 \pm 1.41 \mathrm{~b}$ \\
\hline BNT 5\% & 1.61 \\
\hline
\end{tabular}

Keterangan: 1) Setiap data merupakan rerata dari 3 kali ulangan

2) Angka yang didampingi notasi berbeda menunjukkan perbedaan nyata $(\alpha=0.05)$

Tabel 12 menunjukkan nilai tingkat kekuningan $\mathrm{b}^{*}$ cenderung tetrtinggi diperoleh pada perlakuan rasio jambu biji : belimbing $1: 1$ sebesar 15.95 dan yang tidak berbeda nyata dengan rasio jambu biji : belimbing $1: 2$ sebesar 15.25. Hal ini disebabkan proporsi jambu biji merah lebih rendah dari buah belimbing menyebabkan warna akan dominan menjadi kuning pada produk velva.

Produk velva kombinasi buah jambu biji dan buah belimbing manis, yang memiliki proporsi buah jambu biji yang lebih besar cenderung menghasilkan tingkat kecerahan $L^{*}$ dan tingkat kemerahan $a^{*}$ yang lebih tinggi sedangkan yang memiliki proporsi buah belimbing yang lebih besar cenderung menghasilkan tingkat kekuningan yang lebih tinggi. Hal ini dapat disebabkan kondisi asam pada produk menyebabkan enzim polifenoloksidase menjadi inaktif, enzim polifenoloksidase merupakan enzim yang memeiliki peran dalam proses pencoklatan buah belimbing (Bai et al, 2009 ). Tingkat keasaman yang tinggi cenderung akan menurunkan proses pencoklatan dari produk velva. Salah satu metode untuk mengontrol pencoklatan enzimatis pada produk pangan yaitu dengan pengkondisian asam, misalnya dengan penambahan asam sitrat (Padmadisastra, 2003).

\section{Karakteristik Organoleptik Velva}

\section{a. Kesukaan Terhadap Warna}

Rearata nilai warna velva buah jambu biji kombinasi belimbing manis berkisar antara sampai dengan skala 3.44 samapi 5.04 . Tingkat kesukaan panelis terhadap warna tertinggi pada perlakuan rasio buah jambu biji : buah belimbing 2 : 1 dan konsentrasi gum arab $0.5 \%$. Kemudian kecenderungan tingkat kesukaan panelis terhadap parameter warna velva ditunjukkan pada Gambar 3.

Gambar 3. menunjukan bahwa pengaruh perlakuan penambahan konsentrasi gum arab dan rasio antara buah jambu biji dan buah belimbing terhadap tingkat kesukaan warna velva kombinasi buah jambu biji dan buah belimbing manis sangat fluktuatif, panelis lebih suka produk velva dengan warna merah terang dibandingkan velva dengan warna lebih pucat. 


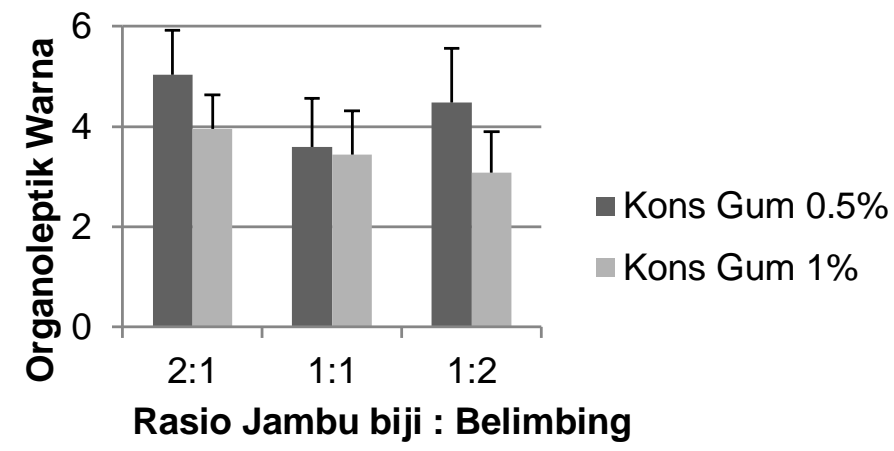

Gambar 3. Grafik rerata organoleptik warna velva

\section{b. Kesukaan Terhadap Aroma}

Rearata nilai aroma velva buah jambu biji kombinasi belimbing manis berkisar antara sampai dengan skala 3.44 samapi 4.52 . Kemudian kecenderungan tingkat kesukaan panelis terhadap parameter aroma velva ditunjukkan pada Gambar 4.

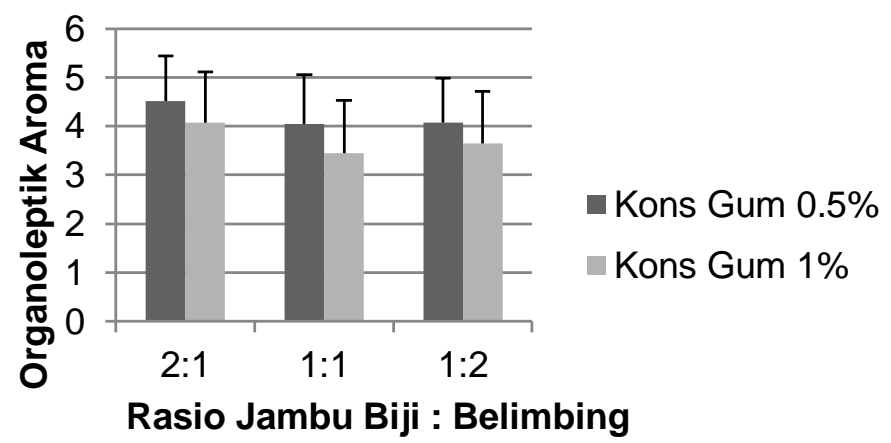

Gambar 4. Grafik rerata organoleptik aroma velva

Gambar 4 menunjukkan bahwa rerata tingkat kesukaan panelis terhadap aroma tertinggi pada perlakuan rasio buah jambu biji : buah belimbing 2 : 1 dan konsentrasi gum arab $0.5 \%$. Sedangkan kesukaan panelis terhadap aroma terendah pada perlakuan rasio buah jambu biji : buah belimbing $1: 1$ dan konsentrasi gum arab 1\%. Panelis cukup menyukai aroma buah jambu yang cenderung kuat pada velva.

Aroma velva disebabkan oleh senyawa-senyawa volatil yang terbentuk selama proses pembuatan. Di gambar 3 menunjukan rerata kesukaan panelis terhadap aroma velva cenderung menurun dengan bertambahnya konsentrasi gum arab. Hal tersebut di duga karena semakin meningkat konsentrasi gum arab, adonan velva akan semakin mengental sehingga zat volatil sulit menguap atau keluar dari adonan velva. Penggunaan satbilizer yang banyak menyebabkan produk yang dihasilkan akan terlalu kental karena stabilizer mampu mengikat sejumlah besar air bebas yang mengandung zat-zat volatil (Hui, 1992).

\section{c. Kesukaan Terhadap Rasa}

Rearata nilai aroma velva buah jambu biji kombinasi belimbing manis berkisar antara sampai dengan skala 3.72 samapi 4.24. Kemudian kecenderungan tingkat kesukaan panelis terhadap rasa velva tiap perlakuan ditunjukkan pada Gambar 5.

Gambar 5 menunjukkan bahwa rerata tingkat kesukaan panelis terhadap rasa tertinggi pada perlakuan rasio buah jambu biji : buah belimbing $1: 2$ dan konsentrasi gum arab $0.5 \%$. Panelis cenderung menyukai rasa velva yang seimbang antara buah jambu biji dan buah belimbing. Tingkat kesukaan rasa ini bisa disebabkan oleh rasa velva yang lebih padat karena pengaruh dari rasio buah belimbing yang lebih banyak dan akibat pengembangan atau overrun yang tidak terlalu besar sehingga lebih banyak yang menyukainya 


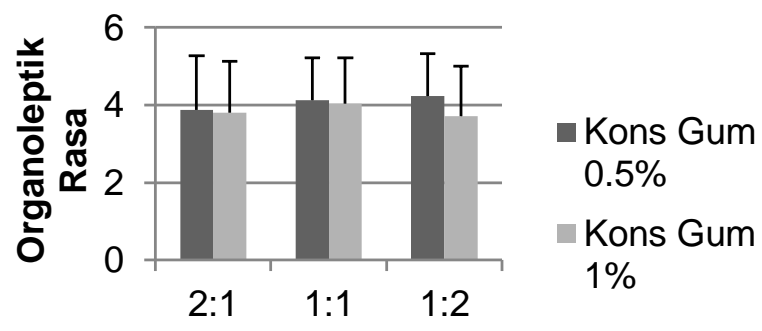

Rasio Jambu Biji : Belimbing

Gambar 5. Grafik Rerata Organoleptik Rasa Velva

\subsubsection{Kesukaan Terhadap Tekstur}

Rearata nilai aroma velva buah jambu biji kombinasi belimbing manis berkisar antara sampai dengan skala 3.44 samapi 3.84. Kemudian kecenderungan tingkat kesukaan panelis terhadap parameter tekstur velva tiap perlakuan ditunjukkan pada Gambar 6 .

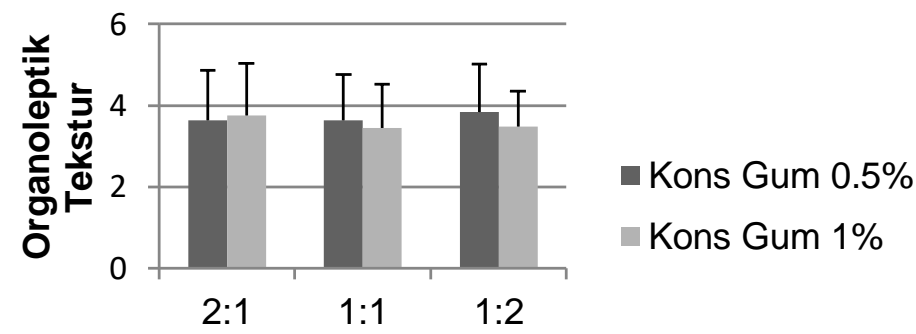

Rasio Jambu Biji : Belimbing

\section{Gambar 6. Grafik Rerata Organoleptik Tekstur Velva}

Gambar 6 menunjukkan bahwa rerata tingkat kesukaan panelis terhadap tekstur tertinggi pada perlakuan rasio buah jambu biji : buah belimbing $1: 2$ dan konsentrasi gum arab $0.5 \%$. Panelis cenderung menyukai produk velva dengan tekstur yang dihasilkan oleh penambahan konsentrasi gum arab $0.5 \%$ dibandingkan penambahan $1 \%$.

Parameter penilaian tekstur dapat dilihat dari sifat icy atau sandy dari es krim. Sifat icy merupakan cacat tekstur yang disebabkan oleh adanya kristal es yang dirasakan ketika es krim dimakan. Penambahan sukrosa diduga mampu mecegah terbentuknya icy karena sukrosa memiliki sifat dalam menurunkan titik beku sehingga diharapkan kristal es yang terbentuk lebih kecil (Goff, 2002). Tekstur velva yang baik adalah halus dengan kristal es yang kecil.

\subsection{Perlakuan Terbaik}

Pemilihan perlakuan terbaik pada produk velva buah jambu biji kombinasi belimbing manis dilakukan dengan menggunakan metode multiple attribute (Zeleny,1982), dimana setiap parameter dianggap memiliki bobot yang sama penting. Pemilihan parameter berdasarkan faktor kepentingan dan nilai pengharapan yang terbaik untuk mendapatkan nilai perlakuan terbaik.

Berdasarkan hasil perhitungan nilai perlakuan terbaik (Lampiran 16) didapatkan velva kombinasi buah jambu biji dan belimbing manis dengan perlakuan terbaik terhadap sifat kimia fisik dan organoleptik yaitu pada perlakuan rasio buah jambu biji : belimbing manis $1: 1$ dengan konsentrasi gum arab $0.5 \%$. Karakteristik fisik-kimia dan organoleptik velva perlakuan terbaik disajikan pada Tabel 13.

Penelitian ini menunjukan bahwa perlakuan konsentrasi velva rasio buah jambu biji : belimbing manis $1: 1$ dengan konsentrasi gum arab $0.5 \%$ memberikan hasil yang terbaik dari sifat fisik dan kimia serta organoleptik. Namun, nilai parameter organoleptik masih tergolong 
cukup rendah sehingga dibutuhkan reformulasi lebih lanjut untuk meningkatkan nilai parameter organoleptik sehingga daya terima konsumen akan meningkat.

Tabel 13. Karakteristik Fisik, Kimia, Dan Organoleptik Velva Buah Jambu Biji Kombinasi Belimbing Manis

\begin{tabular}{lc}
\hline Parameter & Nilai pengharapan \\
\hline $\mathrm{pH}$ & $3.64 \pm 0.13$ \\
Kadar Serat Kasar (\%) & $0.86 \pm 0.21$ \\
Persentase Aktivitas Antioksidan & $10.19 \pm 0.32$ \\
$(\%)$ & $14.46 \pm 2.76$ \\
TPT ('Brix) & $13.01 \pm 0.24$ \\
Overrun (\%) & $20.84 \pm 2.32$ \\
Kecepatan Meleleh (menit/10 g) & $45.26 \pm 1.53$ \\
Kecerahan $\mathrm{L}^{*}$ & $11.03 \pm 0.20$ \\
Kemerahan $\mathrm{a}^{*}$ & $16.16 \pm 1.07$ \\
Kekuningan $\mathrm{b}^{*}$ & Suka) \\
Warna & $4.60 \pm 0.95$ (Agak Tidak Suka - Agak \\
& $4.12 \pm 1.01$ (Agak Suka) \\
Aroma & (Agak Suka) \\
Rasa & Suka) \\
Tekstur & $3.64 \pm 1.11$ (Agak Tidak Suka - Agak \\
& \\
\hline
\end{tabular}

Keterangan: 1) Setiap data analisis fisik dan kimia merupakan rerata dari 3 kali ulangan

2) Nilai parameter hedonik merupakan rerata data nilai dari 25 panelis

\section{SIMPULAN}

Velva kombinasi buah jambu biji merah dan buah belimbing merupakan salah satu frozen desert yang serupa dengan es krim, yang mempunyai kelembutan dan kelezatan yang hampir sama dan bahan bakunya adalah buah. Hasil perlakuan terbaik untuk pembuatan Velva kombinasi jambu biji merah dan belimbing dengan parameter fisik, kimia, dan organoleptik adalah perlakuan dengan rasio buah jambu biji : belimbing $1: 1$ dengan konsentrasi gum arab $0.5 \%$ dengan karakteristik dengan karakteristik $\mathrm{pH} 3.64$; kadar serat kasar $0.86 \%$; aktivitas antioksidan 10.19\%; TPT $14.46^{\circ}$ Brix; overrun 13.01\%; kecepatan meleleh 20.84 menit/10 gram; kecerahan $L^{*}$ 45.26; kemerahan $a^{*} 11.03$; dan kekuningan $b^{*} 16.16$. Kemudian perlakuan terbaik terhadap organoleptik yaitu dengan nilai hedonik dengan skala 1-6 (sangat tidak suka sampai sangat suka) pada warna 3.60; aroma 4.04; rasa 4.12; dan tekstur 3.64.

\section{DAFTAR PUSTAKA}

Andarwulan, N., dan Koswara, S. 1992. Kimia Vitamin. Jakarta: Rajawali Press.

Bai, J., J. Nercisco, A. Plotto, and E. Baldwin. 2009. Harvest Inventory, Pre Cutting wash, and post-processing dip to Quality of Fresh Cut Carambola Fruits. Proc Fla State Hoet.

Frandsen dan Arbuckle (1961) di dalam Maria, Devrina Nova, Zubaidah, Elok. 2014 Pembuatan Velva Jambu Biji Merah Probiotik (Lactobacillus acidophilus) Kajian Persentase Penambahan Sukrosa dan CMC. Jurnal Pangan dan Agroindustri 2:4,1828.

Frandsen dan Arbuckle (1986) di dalam Maria, Devrina Nova, Zubaidah, Elok. 2014 Pembuatan Velva Jambu Biji Merah Probiotik (Lactobacillus acidophilus) Kajian Persentase Penambahan Sukrosa dan CMC. Jurnal Pangan dan Agroindustri 2:4,1828. 
Goff, H. 2002. Ice Cream. Dairy Science and Technology on The Internet. www. foodsci.uoguelph.ca/dairyedu/icecreamhtml. Tanggal akses: 26 Juni 2018.

Hui, Y. H. 1992. Encyclopedia of Food Science and Technology. Volume II. John Willey and Sons Inc, Canada

Kurultay S., Oksuz O., Gokcebag O. 2010. The Influence of Different Total Solid, Stabilizer, and Overrun Levels in Industrial Ice Cream Production using Coconut Oil. J Food Processing Preservation. 34: 346-354.

McCue, K. 2002. Salting Roads. (www.chemistry.org/portal/chemistry/PID=featureent.htm). Tanggal akses: 25 Juni 2018.

Musaddad D., Hartuti N. 2000. Produk Olahan Tomat. Depok. Penebar Swadaya

Padmadisastra, Y., Sidik, and S. Ajizah. 2003. Formulasi Cair Gel Lidah Buaya (Aloe Vera Linn.) Sebagai Minuman Kesehatan. Simposium Nasional Kimia Bahan Alam III. 1-13

Soedarya, A. P. 2009. Agribisnis Guava (Jambu Batu). Bandung: Grafika Pustaka.

Sukadana, I. M. 2009. Senyawa Antibakteri Golongan Flavonoid dari Buah Belimbingmanis (Averrhoa carambola L.). Penelitian Kimia Organik Bahan Alam jurusan Kimia FMIPA Universitas Udayana.

Tan CP, Mirhosseini H, Aghlara A, Hamid, NSA, Yusof S, Chern BH. 2008. Influence of Pectin and $\mathrm{cmc}$ on Phisical Stability, Turbidity Loss Rate, Cloudiness and Flavour Release of Orange Beverage Emulsion During Storage. J Carbohydrate Polymares, 73, 89-91.

Wijaya, H.C. 2002. Pangan Fungsional dan Kontribusinya Bagi Kesehatan. Seminar Online Kharisma ke-2 